Affect, Technoscience and Textual Analysis : Interrogating the Affective Dynamics of the Zika Epidemic through Media Texts

\title{
Oikkonen, Venla
}

2017-10-01

Oikkonen, V 2017 , ' Affect, Technoscience and Textual Analysis : Interrogating the Affective Dynamics of the Zika Epidemic through Media Texts ' , Social Studies of Science, vol. 47 , no. 5 , pp. 681-702 . https://doi.org/10.1177/0306312717723760

http://hdl.handle.net/10138/308920

https://doi.org/10.1177/0306312717723760

acceptedVersion

Downloaded from Helda, University of Helsinki institutional repository.

This is an electronic reprint of the original article.

This reprint may differ from the original in pagination and typographic detail.

Please cite the original version. 
Please cite the published version: Social Studies of Science 47(5): 681-702

doi: $10.1177 / 0306312717723760$

\title{
VENLA OIKKONEN
}

\author{
Affect, technoscience and textual analysis: Interrogating the affective dynamics of the Zika \\ epidemic through media texts
}

\begin{abstract}
:
Science and Technology Studies has become increasingly interested in the roles of affect and emotions in science and technology. Researchers have examined, for example, emotions in the production of scientific knowledge, patients' or users' affective experiences of technologies, and emotionally charged cultural representations of science. However, less attention has been paid to the underlying affective dynamics that connect these sites, experiences and representations. This article builds on the premises that, first, unpacking these underlying affective dynamics is pivotal to understanding emerging technoscientific phenomena, and, second, that such affective dynamics often need to be accessed through cultural texts such as media. This necessitates developing tools of textual analysis that can capture cultural emotions, affective intensities and the tensions and resonances that arise when affective intensities and culturally circulating emotions become entangled. To this end, the article develops methods of textual analysis through a case study: the affective dynamics underlying the Zika epidemic. Focusing on the New York Times coverage of the epidemic, the article identifies affective concentrations centering on temporality, invisibility, and the dissolution of material boundaries. It shows that there are considerable tensions both within and between these concentrations, and that such tensions engender affective intensities and emotional investments. By combining discursive and non-discursive dimensions of the affective dynamic of Zika, the analysis contributes to the growing STS methodological literature on affect and emotion in technoscience.
\end{abstract}

Keywords: affect, emerging infectious diseases, emotion, epidemics, media, microcephaly, qualitative methods, Zika

In October 2015, many scientists, medical professionals and journalists turned their attention to the Zika epidemic underway in Brazil. This interest did not arise from the disease itself: Most Zika patients had mild symptoms, and the virus was not new - the first human Zika infection had been reported in Africa already in the 1950s, and local epidemics had been documented in the Pacific region since 2007. What caused the alarm in October 2015 were reports of an increase in microcephaly - arrested growth of the head and the brain - among babies born to women in the Zika affected regions of Brazil. The suspected link between Zika and microcephaly profoundly transformed the affective underpinnings of the arising epidemic. As Zika travelled across South and Central America, and, in summer 2016, into North America, and as accumulating evidence supported the connection between Zika and microcephaly, the epidemic emerged as a multi-sited technoscientific phenomenon deeply entangled with anxieties, fears, hopes, and anticipation. These affective underpinnings, in turn, took shape through gendered, sexualized and racialized imaginaries involving pregnant bodies, transnational sexual relationships and the material conditions of Brazilian favelas and rural outpatient clinics. 
The Zika epidemic demonstrates that affect and emotions play a key role in technoscientific phenomena such as emerging infectious diseases and their technoscientific management, and that understanding such phenomena requires methods that address their affective and emotional dimensions. In this article, I use the affectively charged discourses surrounding the Zika epidemic as a case study through which I develop methods for analysis of affect and emotions in technoscience. More specifically, I develop methods of textual analysis to trace affective dynamics underlying multi-sited technoscientific phenomena. In so doing, the article contributes to ongoing discussion within science and technology studies (STS) on affect and emotion. STS scholars have been increasingly interested in the ways in which affect and emotions shape how science and biotechnologies are conceptualized and experienced in society. One strand of research has centered on emotions and affective relations in the practices of science. For example, Myers (2015) shows how protein modelers engage affectively with the objects they study and how matter emerges as 'excitable', and Parker and Hackett (2012) analyze the role of emotions and emotionally charged atmosphere in collaborative theoretical work on interdisciplinary questions. ${ }^{1}$ Another strand of research has explored the role of emotions in how publics engage with science. This strand includes analyses of mass mediated and institutional representations of science and biotechnology. For example, Masco (2008) shows how Cold War era documentaries and educational films on a possible nuclear attack against the United States sought to turn unproductive terror into manageable and productive forms of fear within a nationalist framework. $\stackrel{2}{-}$ A third strand of research explores the emotional responses of patients or users of technologies. $\frac{3}{}$ Many STS scholars have highlighted how such responses are entangled with the materiality of technologies. For example, Oudshoorn (2015) analyzes how pacemakers and implantable cardioverter defibrillators are embodied and emotionally experienced technologies that may appear to have an agency of their own, and Meskus (2015) analyzes the entanglement of embodied emotions and the attribution of agency to embryos, hormones, and material bodily processes among women undergoing infertility treatment.

Instead of focusing on specific practices or embodied experiences, however, I turn to the affective dynamics that underlie a technoscientific phenomenon, that is, the ways in which technoscientific phenomena take shape through collectively registered affective intensities and circulating cultural emotions. I highlight the shifting entanglements of affect and emotions in technoscience, and their role in co-constituting technoscientific phenomena. My approach to affective dynamics draws on Ahmed's (2004) and Pedwell's (2014) work on the webs of cultural circulation through which emotions and affect emerge at different sites. Ahmed refers to this dynamic as affective economies and circulation of emotions, while Pedwell conceptualizes it as affective relations. I take the circulation of affect and emotions across technoscientific sites as my starting point. While there exists a rich tradition of ethnographic studies of embodied experiences within STS, the investigation of the affective dynamics of technoscientific phenomena also requires methods that can capture the affective intensities and circulating emotions through cultural texts.

The article builds on a conceptual distinction between affect and emotion. Affect is often understood to refer to non-discursive intensities and sensations - the sense of rhythm or movement, for example. Emotion, in turn, resides more clearly in the discursive realm: Emotions are socially produced and culturally circulated. The distinction between affect and emotion has proven useful especially in work that seeks to capture unconsciously sensed shifts and (in)stabilities, or the potentiality of bodies to be affected. ${ }^{4}$ While investigations of affective forces and intensifications provide one important starting point for my approach, my focus on collective affective dynamics extends the analysis to cultural structures and discursive relations that underlie technoscientific phenomena. Such structures and relations are profoundly shaped by the circulation and historical layered-ness of emotions as semi-public entities. I suggest that affective intensities and cultural emotions are often inseparable in the collective affective dynamics of technoscientific phenomena. 
Accordingly, my analysis of the Zika epidemic traces how affect and emotions become entangled in the public understanding of the epidemic. I approach this entanglement as multidirectional: While affective intensities may give rise to emotions (in the sense that they precede emotion), cultural emotions shape how we may become (or fail to become) attuned to affective intensities. In this sense, affective intensities and cultural emotions co-constitute the preconditions of experience. In what follows, I use the terms affect and affective intensities to describe mainly non-discursive or structural aspects, and emotion and cultural emotion to indicate more clearly verbalized aspects, of the collective affective dynamics of technoscientific phenomena. By affective dynamics I refer to the conjoiner of affective intensities and cultural emotions across sites of technoscience, highlighting the collective and public dimensions of how technoscientific phenomena invite us to be affected. (Furthermore, I use the adjective form affective to describe both affective intensities and cultural emotions. Emphasis is on the verb affect: Something that is affective may affect us in unconscious as well as conscious ways.)

Building on this theoretical framework, I trace how affective intensities and cultural emotions transform, and how affect 'accumulates' (Ahmed, 2004) in certain objects through this circulation and repetition. I approach such affective dynamics as materializing in culturally recognizable emotional investments and nonverbal affective intensities, as well as embodied experiences. Crucially, this focus renders cultural formations of emotion or moments of affective intensification as symptoms of the underlying affective dynamic.

The Zika epidemic provides an intriguing case study through which this approach can be developed. The Zika case is packed with shifting and intersecting emotions, and its geographical progression sheds light on affect as a dynamic organized by temporal and spatial movement. Existing scholarship on epidemics and pandemics has shown how emerging infectious diseases evoke a range of emotions - panic, fear, hopes of scientific progress - which shape the practices of people and communities. Emotions also shape how epidemics and pandemics are experienced and represented in society. For example, Wald (2008) and Schell (1997) trace the interplay of emotions and differences such as race, gender and sexuality in the narratives of the emergence and containment of contagious diseases. Others, like Joffe (2011), Mayor et al. (2013), or Goodwin et al. (2011), address variations and changes in how the risk of contracting a pandemic illness is managed in public discourse through emotional responses involving blame and stigmatization of those associated with the origin and spread of the disease. Such studies show that epidemics and pandemics are phenomena in which the minute and material (such as a virus or a vaccine) and the global and abstract (geopolitical relations, global and national pandemic prevention strategies) are interconnected in multiple ways.

While my article draws on the rich research literature on epidemics, my primary goal is not to understand the cultural logics of Zika, but to outline a textual approach that can account for how affective dynamics shape technoscientific phenomena. I am interested in shifts and tensions between affective intensities and emotional investments. By focusing on affective dynamics and the relations between affective intensities and cultural emotions, I hope to capture constellations of material, discursive and non-discursive forces that shape technoscientific phenomena.

\section{Material and methods}

I develop methods for textual analysis of affective dynamics through the New York Times coverage of the Zika epidemic. Science communication scholars have previously explored the quality of risk 
information in print media coverage of infectious disease epidemics (Dudo et al., 2007; Evensen and Clarke, 2012; Roche and Muskavitch, 2003). My approach differs from these studies in that I do not seek to evaluate how print media in general, or even the New York Times in particular, has covered the Zika epidemic, but approach newspaper articles as gateways into the affective dynamics of the epidemic. Furthermore, while some science communication scholars (e.g. Dudo et al., 2007) address the connection between the quality of risk information and 'emotional stress' among the publics, my approach departs clearly from this largely untheorized understanding of emotional responses as locatable in the individual subject. I use the New York Times reporting on the epidemic to sketch a methodological approach that can capture the entanglement of affective intensities and cultural emotions through analysis of texts.

As my primary objective is methodological development, I need a set of data that is focused and concise and yet suggestive of the possibilities of textual analysis of affective dynamics. The New York Times is suitable for this purpose: It addresses a wide national and international audience and we can presume that it seeks to maintain its reputation as a reliable and up-to-date source of information. Furthermore, it has actively covered important scientific, social and political developments through most of the Zika epidemic. It should be noted, however, that the New York Times provides a distinctly North American viewpoint. The 'Zika epidemic' of the United States is not the same as the Zika epidemic of a Brazilian city, where the illness is part of lived, embodied, everyday reality, nor is it the same as the Zika of Northern Europe, where the risk of local transmission is nonexistent due to the absence of the mosquito that carries the virus.

For my case study, I retrieved from the New York Times online site 195 articles on the Zika epidemic published between the beginning of December 2015 and the end of August 2016. The articles were published in a range of newspaper sections including Health, Americas, Politics, Science, Travel, World, U.S., N.Y./Region, Olympics, Editorials, Opinion Pages, Business Day, Asia Pacific, Europe, and even Weddings and Fashion \& Style (the last two reported the impact of Zika on destination weddings and the popularity of designer insect repellents). For each article, I used the version available through the online site. The articles were located using 'Zika' as the search term. The articles span the period from the moment when reports of a suspected connection between Zika and microcephaly in Brazil made the epidemic an internationally noteworthy event to the moment when local transmission of the South American strain of Zika was first reported outside the Americas in Singapore. This temporal span allows me to trace shifts in affective intensities and emotional investments following developments in the epidemiology (means and patterns of contagion), severity and geographical spread of the epidemic. It enables me to examine how the Zika epidemic takes different shapes as an affective phenomenon at different moments during the epidemic.

The span of nine months registers a number of emerging, affectively charged issues around Zika, including: the verification of the connection between Zika and microcephaly, the first babies with microcephaly born in the US to mothers who contracted Zika during travel in South America, the prolonged political conflict over Zika emergency funding between the Obama White House and the Republican-dominated Congress, growing scientific knowledge about the transmission of Zika through sex, and concerns about the approaching 2016 Rio Summer Olympics. Despite its distinctly North American vantage point, the New York Times coverage registers tensions between sites where the illness is experienced and felt affectively; these tensions center on the anticipated spread of the epidemic to the southern states of the US, and on the appearance of the first locally transmitted Zika cases in Florida in July 2016. Such tensions suggest that the epidemic is multiple and heterogeneous at any given moment. By focusing on the multiplicity of the epidemic at a single media site - the New York Times - rather than a range of media sources, I hope to identify specific affective 
mechanisms and thus to highlight nuances and ambiguities in how affect and emotions shape a specific technoscientific site. I propose that my approach in this article could be developed into a more systematic methodology to address the affective dynamics underlying the connections between multiple sites (such as various media outlets and public forums across nations and continents affected by an epidemic), or even multiple technoscientific phenomena (for example, the connections between epidemics, the vaccine industry and antimicrobial resistance). It could also be brought into dialogue with ethnographic research to explore the connections between situated embodied experiences and the cultural circulation of affect and emotions.

In addition to the theorization of non-discursive affect and the cultural circulation of emotions introduced above, I build on narrative analysis and analysis of cultural imaginaries. Narrative analysis provides a useful starting point for analyzing affective dynamics, because it highlights how narrative organization produces a sense of movement, anticipation or closure (e.g. Beer, 2000; Hausman, 2000; Oikkonen, 2013; Roof, 1996; Wald, 2008). That is, narrative organizes events into a temporal sequence (or a set of sequences), while investing that sequence with a sense of causality - indeed, narrative structure shapes what appears as a meaningful narrative event in the first place. Crucially, narrative is more than a mode of representation; narratives condition how we orientate in time and space. Narrative organization produces a sense of movement and temporal orientation that exceeds (and sometimes even contradicts) the explicit words on the page. This makes narrative analysis a helpful tool in understanding how texts move us not only through their language or content but also through their structural, largely non-discursive orientations. Cultural imaginaries, in turn, connect phenomena or events to one another through the fabric of circulating images, tropes, and metaphors (McNeil, 2007; McNeil et al., 2017; Roof, 2007; Stacey, 2010; Van Dijck, 1998). Such images, tropes and metaphors are often deeply affectively charged.

Drawing on this background, my analysis seeks to identify recurring linguistic and narrative elements that suggest emotional investment (culturally nameable emotions such as fear, panic or hope) and affective intensities (for example, a sense of inevitable progression of the epidemic or halted progress of science). In order to capture both articulated and non-discursive aspects of the affective dynamics of Zika, I focus on circulating phrases, recurring ways of speaking and narrating, and structural ways of organizing and framing the epidemic. I pay particular attention to shifts during the examined time frame, that is, to the processes in which an affectively charged element becomes replaced by other affectively charged elements. To ensure a clear analytical focus, I approach only textual material in the articles. A further analysis could include visual elements in the articles - mostly pictures of mosquitoes, deserted backyards or babies with microcephaly which often reinforce the affective powers of Zika imagined in many of the articles.

My reading of the New York Times coverage identifies three concentrated formations of emotion and affect that appear central to the affective dynamics of the Zika epidemic. I will call them affective concentrations. The first one centers on temporality. It juxtaposes multiple temporalities, including those of the progression of the epidemic, the onset and development of symptoms, the progression of a pregnancy, the promises and failures of scientific progress, the preparations and worries about the approaching Olympics, and the ongoing political battle over US Zika funding. I suggest that tensions and resonances between these parallel temporalities play a major part in the production of affective intensities and emotional investments. The second concentration centers on invisibility. The analysis suggests that the affective dynamics of the Zika epidemic arise to a considerable extent from multiple invisibilities. These involve the often invisible Aedes aegypti mosquito, the absence of symptoms in most people infected with Zika, the invisibility of microcephaly until late in pregnancy, and the invisibility of the virus itself in many early diagnostic tests. The third concentration centers on the dissolution of material boundaries. My analysis 
suggests that much of the affective turmoil in the Zika epidemic is connected to how boundaries become blurry through the unpredictability of nonhuman entities such as the mosquito and the virus, or the unpredictability of molecular and neurological processes inside the uterus and in the fetal brain. In what follows, I dedicate one section to each of these affective concentrations, and then I draw connections between the three affective concentrations in a further section.

\section{Temporality}

The New York Times coverage of the Zika epidemic spells out clearly that Zika is an affective issue: The articles repeatedly refer to 'fear', 'panic', 'anxiety' and 'worry'. For example, in an article published in January 2016, a medical specialist from Vanderbilt University is quoted as saying: 'This is a virus with a strange name, an international origin and potentially horrendous consequences. ... This is going to be enormously anxiety-provoking' (McNeil, 2016a). Similarly, a January 2016 opinion piece by the Director of the Center for Infectious Disease Research and Policy at the University of Minnesota is titled: 'How scared should you be about Zika?' (Osterholm, 2016).

Throughout the coverage of the epidemic, such invocations of affect and emotion are entangled with, and emerge through, questions of temporality. STS critiques of temporality have shown that ideas of progress and future-orientation play a foundational role in technoscientific societies, and that they often render alternative temporalities inconceivable (Adams et al., 2009; Puig de la Bellacasa, 2015). Assumptions of scientific progress play a key role in discourses and narratives of contagious diseases. For example, in her historical analysis of the transformations of the 'outbreak narrative', Wald (2008) identifies a narrative pattern that casts epidemics as temporal events characterized by a race between an invasive virus or bacterium and the scientists seeking to contain the outbreak. Such assumptions of progress reflect larger cultural investments in science that posit science as a promise of futurity, the continuation of human societies; this becomes visible, for example, in Turner's (2007) analysis of the temporal investments underlying the prospect of cloning extinct species. However, while science is often seen as a temporal, future-oriented project, it is nevertheless affectively ambivalent, as suggested, for instance, by Franklin's (2007) analysis of the affective investments underlying the cloning of Dolly the sheep. Nor are expectations of progress stable. Instead, they arise from dynamic relationships between science and its publics (Horst, 2007).

The New York Times coverage of the Zika epidemic documents the Zika outbreak and progressing epidemic as temporal events. Several articles tell us that the Zika virus was first identified in a rhesus monkey in the Zika forest in Uganda in Africa. The first known human infection was reported in 1952, and the Zika virus, a mosquito-borne flavivirus related to yellow fever, dengue, West Nile virus and Japanese encephalitis, was isolated from a young girl in Nigeria in 1954. Compared with other mosquito-borne illnesses, Zika was considered mild: It caused symptoms in only about 20 percent of those infected, and the symptoms were usually limited to fever, rash, aching joints and conjunctivitis (eye infection). This narrative posits Zika as dormant and time as moving slowly and expectedly. The year 2007 is cast as the moment when the pace changes, as a Zika outbreak on the Pacific island of Yap infects the majority of the population. The year 2013 brings Zika outbreaks in French Polynesia and other Pacific islands, and the Confederation Cup tournament in Brazil in the summer 2013 is constructed in retrospect as the moment when the Zika virus crossed the ocean from Polynesia to South America inside the body of a Zika-infected traveler and was picked up by Brazilian Aedes aegypti mosquitoes. The sense of temporal movement intensifies with the first confirmed cases of Zika in northeastern Brazil in the spring of 2015 and 
especially with the announcement in October 2015 of a sharp increase in cases of microcephaly in babies born to women infected with Zika during pregnancy. At the same time, temporality appears as rife with emotions, such as fear, empathy or grief, as well as with affective potentiality, such as the sense of the present shaping the future in unforeseen ways. Crucially, these temporal intensifications are constructed in retrospect: The first New York Times articles on Zika identified through my search were published in December 2016.

In the New York Times articles, both affect and emotions take shape through the intertwining of temporal and geographical movement. Throughout the epidemic, the articles document the spread of the epidemic across Latin America and the Caribbean - typically captured in a growing list of countries with local Zika transmission - and toward the southern border of the United States. While the texts appear to express genuine concern about the health of South and Central Americans, a lot of affective weight is placed on the predicted crossing of the epidemic to North America. As early as December 2015, an article cautions that ' $[\mathrm{t}]$ he Zika virus has already reached several countries in Latin America, including Mexico, and the Centers for Disease Control and Prevention warns that it could spread in parts of the United States as well' (Romero, 2015). A January 16 piece reports that a 'C.D.C. epidemiologist recently predicted that Zika would follow the same pattern that dengue has, with local transmission during hot weather in tropical parts of the country, including Florida, the Gulf Coast and Hawaii' (McNeil, 2016b). Furthermore, a January 28 editorial renders visible the affective stakes of the temporal and spatial progression of the epidemic, as it describes how the virus is 'sweeping through South and Central America ... and is threatening to invade the United States' (New York Times, 2016). The emergence of military and border metaphors is not surprising. As researchers studying social dimensions of infectious disease outbreaks have argued, the geographical spread of epidemics is often conceived in terms of national threats, and the attempts to contain those threats are conceptualized as (semi)military operations (Joffe, 2011; Levina, 2015; Wald, 2008; Washer, 2010). This gives the temporal and spatial progression of the epidemic a sense of affective urgency, as when an article published on February 12 tells us how '[n]early a year after the first cases of Zika were diagnosed in Brazil, the virus, which is suspected to cause birth defects and other neurological problems, is bearing down on American shores' (Tavernise, 2016b). In this quotation, temporal movement, the perceived sanctity of borders threatened by Zika, and the tumultuous affective intensities surrounding microcephaly emerge as fundamentally entangled.

The affective underpinnings of the progression of the Zika epidemic across Central America towards North America are emphasized through the sense of inevitability that many of the articles invoke. An April 8 opinion piece by the dean of the National School of Tropical Medicine at Baylor College of Medicine titled 'Zika is coming' spells out this inevitability (Hotez, 2016). The text invokes the vulnerability of boundaries by portraying Zika as 'a potentially devastating health crisis headed for our region'; it establishes the temporal urgency by stating that 'we might have only [a] few weeks to stop it before pregnant women become infected'; and it depicts an affectively invested scene of dormant but inevitable tragedy: 'It's only April, but temperatures are hitting the 80s in the afternoons, and Aedes mosquitoes are already here. ... If we don't intervene now, we could begin seeing newborns with microcephaly and stunted brain development on the obstetrics wards in one or more of these places [big cities in the south such as Houston, New Orleans, and Miami]' (Hotez, 2016).

This sense of inevitability is reinforced through what could be called affective rhetoric of numbers. In addition to the growing list of countries with local Zika transmission, the articles report the growing number of microcephaly cases in different countries (including babies born to US residents who contracted Zika while traveling in Latin America), the number of pregnant women with Zika diagnoses in different countries (including the US), the cases of Zika contracted through different 
types of sex in the US and Europe (male to female, female to male, male to male), and, in July and August 2016, the growing number of locally acquired Zika infections in Florida. These constantly growing numbers reinforce the sense of unstoppable movement. At the same time, their perceived indisputability emerges as a force capable of moving emotions such as fear and anxiety. Human suffering and anxiety is translated into numbers, and these numbers also engender and shape anxiety. It is important to remember, however, that numbers are produced through practices of registering and measuring illness - both socially and historically shaped practices. They are also circulated through practices of citation, which, as STS scholarship has extensively shown, reflect and reinforce naturalized practices and power relations in the production of knowledge.

A crucial part of this temporal affective dynamic is the portrayal of science and government intervention as racing with and against the epidemic. The articles introduce and discuss various scientific, medical and technological solutions to the epidemic: the development of diagnostic tests, the possibility of developing a Zika vaccine, the growing understanding of mechanisms of transmission (especially transmission via sex and blood) and of the causal mechanisms between Zika and microcephaly, the development of genetically engineered or radiologically altered mosquitoes to reduce mosquito populations, and new methods of using insecticides. These promised or desired interventions constitute a parallel temporality to that of the Zika epidemic itself. Drawing on cultural discourses of progress surrounding science and technology, many of the articles suggest that such interventions may be able to halt the inevitable forward-reaching temporality of the epidemic. As a result, the forward-looking temporality of these interventions emerges as entangled with the temporality of the epidemic. A February 12 article that compares Zika preparedness to the arrival of dengue in Key West, Florida, in 2009 provides an illuminating description of this dual, intertwined temporality: After the first cases of dengue were reported, '[w]ithin hours, a SWAT team of 30 mosquito experts was going house to house, dumping standing water from flower pots, ashtrays, children's swimming pools, recycling containers, bottle caps and trash cans. They worked 10 hours a day, six days a week, for six weeks, marking their progress on maps' (Tavernise, 2016b). Speed emerges here as an affective force: Competing with the affective temporality of the epidemic that engenders growing fears and anxieties, the speed of scientific and government intervention moves emotions and produces affective intensities by making the material conditions of everyday life an object of concern, anxiety, and hope.

But the progress of science and technology does not always appear smooth and straightforward. For example, several New York Times articles caution the readers that a vaccine is still possibly years away (e.g. Cumming-Bruce, 2016), or that a single person unwilling to get rid of stagnant pools of water in their backyard may undo the efforts of eradicating the Aedes aegypti mosquito in the whole neighborhood (e.g. Tavernise, 2016b). Perhaps most interestingly, several articles point to an inherent contradiction in science itself: The more we learn about the object of study, the more unknown issues emerge. In the case of Zika, science keeps revealing 'alarming new aspects of the virus' (Hirschfeld Davis, 2016). These aspects include more ways in which Zika can be contracted (such as various sexual practices and bodily fluids) and multiple ways in which the virus affects a fetus. This contradiction is captured in a quotation from the head of the World Health Organization, Margaret Chan: 'The knowledge base is building rapidly. ... The more we know, the worse things look' (Tavernise, 2016a). Likewise, the director of the Centers for Disease Control and Prevention (CDC) in the US, Thomas R. Frieden, is quoted as saying: 'The more we learn about Zika, the more concerned we are' (Santora, 2016b). While seeking to alleviate anxieties raised by the epidemic, the scientific study of the virus ends up engendering rather than diminishing emotions such as fear. This renders the seemingly future-oriented temporality of science inherently ambivalent. 
The mutually embedded temporalities of the epidemic and science are further complicated by what could be called microtemporalities. These include the temporality of pregnancy. The 40 weeks of human gestation are perceived in the news articles through the distinction between risky and less risky periods, as the initial reports suggest that the women who contract Zika in early pregnancy face the highest risk of microcephaly. Crucially, one of the heightened anxieties produced by science in the course of the epidemic is the observation in March 2016 that ' $[\mathrm{t}] \mathrm{he}$ Zika virus damages many fetuses carried by infected and symptomatic mothers, regardless of when in pregnancy the infection occurs, according to a small but frightening study released on Friday by Brazilian and American researchers' (McNeil and Saint Louis, 2016). In addition to intensifying the affective stakes of pregnancy during the Zika epidemic, the report reinforces the sense that pregnancy constitutes its own temporality outside the forward-marching temporality of the epidemic. As one pregnant woman from Florida interviewed for an August 2016 article sees it, her goal is to go without a single mosquito bite for nine months (Rabin, 2016). Unlike the ongoing, seemingly endless epidemic, the affective temporality of pregnancy is hoped to end with a clear closure that engenders relief - the birth of a healthy child. Another interesting microtemporality is that of risky periods for sex or blood donations after possible exposure to Zika. The coverage registers changes in recommendations on how long to use condoms or abstain from sex, how long to delay pregnancy, and how long to wait before donating blood, for those returning from areas with local Zika transmission. While these periods of heightened risk are products of measurement techniques and estimates negotiated among public health officials, they also emerge as constituting their own closed temporalities, leading from heightened risk to lesser risk to no significant risk. Here the passage of time is reassuring, yet the very need for the recommendation mobilizes anxieties.

Although the microtemporality of pregnancy and the microtemporality of risky/no-longer-risky periods for sex and blood donation both depart from the forward-moving temporality of the epidemic and science, they become part of another future-oriented temporality - the reproductive future of people and nations. Many articles about the then-approaching Olympics make this clear by speculating on how a Zika infection at the Olympics might shape an athlete's reproductive future by affecting not only current pregnancies but also the 'children they may have one day' (Macur, 2016). While the above quotation refers to female athletes, the theme reappears in accounts about male athletes who decide to freeze their sperm before traveling to the Olympics. Crucially, such language and such measures go well beyond the official recommendations of delaying pregnancy after a Zika diagnosis. Indeed, one article translates these concerns into species terms by suggesting that 'the virus strikes at the heart of what keeps humankind going: our ability to reproduce' (Santora, 2016a). Such future-oriented references suggest that the micro-temporalities of pregnancy and critical periods of bodily contact and potential contagion constitute crucial cracks in the seemingly straightforward temporality that underlies future-oriented science and assumptions of continuing societal stability.

All in all, the New York Times coverage of the Zika epidemic indicates that temporality plays a crucial role in the epidemic, constituting a force that engenders and moves affective intensities as well as emotions. It also shows that this temporality is multiple and thereby ambivalent. There is a strong sense of temporal movement driven by and encapsulated in the progression of the epidemic on the one hand, and the science that studies it on the other. At the same time, this forward orientation is complicated by the microtemporalities of pregnancy and risky periods of bodily contact, as well as the way in which science may produce more uncertainty than it resolves. This presence of multiple temporalities produces structural tensions that engender, mobilize and refashion affective intensities - for example, a sense of the opening or closing of a future - and emotions - for example, anxiety about the presence of mosquitoes, hope in the ability of science to 
address crises, relief at the happy ending of pregnancy, and grief or a sense of vulnerability at the birth of a child with microcephaly. Furthermore, despite their discrepancies, these multiple temporalities also find support from their intersections, as when the temporality of pregnancy emerges as affectively significant through the context of the progressing epidemic. This suggests that temporalities derive some of their power to affect from one another. In order to understand epidemics as affectively organized technoscientific phenomena, we need to address their complex temporal underpinnings.

\section{Invisibility}

The second affective concentration I wish to explore is invisibility, a central theme in the New York Times coverage of the Zika epidemic. Invisibility and visibility play a key role in discourses surrounding science. Especially following the development of increasingly sophisticated imaging technologies, one central objective of science has been to make visible, and thus knowable, what cannot be seen with the naked eye. With technologies ranging from X-ray, ultrasound, functional magnetic resonance imaging (fMRI) and computer tomography to high-power microscopes, advanced genetic sequencing technologies and computer modelling, the interior of the human body and minuscule molecular processes have emerged as signifying the progress of science and have thus become symbolic of knowledge. While many STS scholars have shown that images produced through such technologies rely on context-dependent calculations, measurements based on convention, and personal and professional judgment, rather than an unmediated material reality (e.g. Joyce, 2008; Prasad, 2005), visuality retains its epistemic and rhetorical appeal in popular discourses of science. At the same time, invisibility has come to stand for the challenges still to be encountered by science, or the perceived failures of science to capture and translate the material processes with which, and in which, we live.

Bearing this in mind, it is no surprise that the many forms of invisibility associated with the Zika virus in the New York Times appear as a considerable source of affective intensities as well as emotional responses. As one article puts it: 'Zika is an enemy most people cannot see' (Belluck, 2016d). This affective power of invisibility is particularly strongly felt because it is associated with several aspects of the epidemic. First, the majority of those infected with the Zika virus lack symptoms, and thus the spread of the virus can go unnoticed. In the course of the epidemic, New York Times articles establish a growing concern about the role of asymptomatic people transmitting Zika through sex or through a vector (Aedes mosquitoes, primarily Aedes aegypti) to other people, or to a fetus. In this sense, Zika differs clearly from the violent visuality of the 2013-2014 Ebola outbreak. At the same time, these invocations of invisible symptoms resonate with how the socalled 'healthy carrier' has been historically represented as a source of anxiety (e.g. Wald, 2008).

One key attempt to make Zika visible has been the development of diagnostic tests. While such tests do not actually produce images, they are framed rhetorically as visualizing technologies in the news coverage, as they help render the spreading of the epidemic traceable. Crucially, the invisibility (and gradually increasing visibility) of Zika infection and transmission intersect with the temporalities of the progression of the epidemic and scientific progress examined in the previous section. This intertwining places the invisibility of Zika symptoms and the development of diagnostic tests within a forward-moving temporal trajectory, suggesting that Zika needs to be visualized urgently. The affective power of the invisibility of Zika transmission thus arises not only from the representation of invisibility as a challenge for science but also from the sense of emergency that the seemingly inevitable temporal progression of the Zika epidemic generates. 
The second aspect of invisibility concerns the behavior of the Aedes aegypti mosquito. The mosquito is repeatedly characterized as stealthy and sneaky, as it lives out of the sight in the dark corners of human dwellings. An article published on February 12 quotes the CDC Director Frieden's description of the Aedes aegypti mosquito as 'the cockroach of mosquitoes. ... It lives indoors around people and hides in dark places' (Tavernise, 2016b). Like the invisibly spreading virus, the mosquito is represented as a challenge for science due to its invisibility. This mutual association of the virus and the mosquito with invisibility is affectively powerful, as suggested by the repeated invocation of both (often in connection with one another) throughout the nine months of coverage analyzed here. It is as if their parallel invisibility rendered the virus and the mosquito a particularly mighty dual enemy. These invocations of treacherous invisibility gain further affective weight through the forward-marching temporality of the progressing epidemic. While the mosquito is represented as lying dormant and thus fully invisible during the winter in southern US states, the underlying temporality of the epidemic makes its emergence an inevitability. Crucially, this way of framing the mosquito as a distinct enemy differs radically from the idea of 'the politics of entanglement' proposed by Nading (2014) to describe how people, mosquitoes, urban environment and social, cultural and medical practices co-constitute dengue, an illness also transmitted by the Aedes aegypti mosquito.

The third kind of invisibility that moves emotions and affective intensities is the invisibility of microcephaly under ultrasound until late in pregnancy. Many of the articles highlight that an ultrasound examination can detect microcephaly and related structural changes only toward the end of the second trimester, and even then only in some cases. The limits of visibility are outlined clearly in a July 2016 New York Times article by Laurie Garrett, a well-known writer on emerging infectious diseases: 'New research shows that a woman can become infected with Zika, have no symptoms, yet give birth to a baby with microcephaly. No test administered during pregnancy, including sonograms and blood analysis, can tell would-be parents definitely whether their child has been infected, and identify damage to the fetus' (Garrett, 2016). Many of the articles describing pregnant women living in areas with local Zika transmission emphasize fears and anxieties generated by the invisibility of microcephaly during pregnancy, a journalistic framing that highlights the limits of medical imaging technologies while insisting on their affective power. Social scientists have shown how prenatal sonograms are used to produce emotional responses, whether to strengthen parental attachment to the unborn baby (Han, 2009) or to advocate antiabortion legislation by showing the fetus as an almost fully formed child (Palmer, 2009). However, in the case of Zika, invisibility powerfully moves emotions.

The affective weight of invisibility under an ultrasound device is made particularly potent through its striking contrast to the visible physical features of microcephaly in babies born with the condition, a crucial part of the visual imagery in news reports about Brazilian hospitals and outpatient clinics throughout the Zika epidemic. This contrast produces a tension, as both the invisibility of prenatal changes in the brain and the visibility of unusually small head circumference in babies with microcephaly may evoke a range of emotions and affective responses. Crucially, this contradictory invisibility/visibility of microcephaly emerges at the intersection of several temporalities, most importantly the microtemporality of pregnancy, the seemingly inevitably forward-moving temporality of the progressing epidemic, and the future-oriented (though inherently unstable) temporality of science. These underlying, mutually contradictory temporal strivings render the invisibility/visibility of microcephaly an affective force that shakes people and communities in ambivalent and contradictory ways, depending on their locations within the global networks of wealth, medicine, science and environment. 


\section{Dissolution of material boundaries}

A third affective concentration in the New York Times coverage of the Zika epidemic arises around the perceived dissolution of material boundaries and redistribution of agency. In the past decade in particular, there has been a lot of interest in STS - both within and outside the field known as 'new materialisms' - in rethinking biological matter, embodied materiality, and material practices and technologies as active participants in the production of scientific objects and experiences of health and illness. For example, several scholars have sought to reconceptualize microbes and other nonhuman actors within and outside bodies as part of an interactive (or in Karen Barad's terms, intra-active) dynamic of emergence and historical change (e.g. Barad, 2007; Hird, 2009; Hustak and Myers, 2012; Irni, 2016; Landecker, 2016). Some studies have addressed the agency of nonhuman entities in the context of affect and emotions. These explorations have included analyses of how humans respond emotionally to the perceived unpredictability of nonhuman agency (e.g. Meskus, 2015; Oudshoorn, 2015), as well as analyses of nonhuman acts or cross-species engagements as an affective force (Hustak and Myers, 2012; Puig de la Bellacasa, 2015).

Material entities and processes play a constitutive role in the New York Times coverage of the Zika epidemic. Material objects help spread the virus, as when standing water in backyard pools, outdoor containers and bottle caps, and even 'a few milliliters of water that have dribbled into a toothbrush holder' (Jacobs, 2016) serve as potential breeding grounds for the Aedes aegypti mosquito. Material objects also become part of attempts to control the virus, as when insect repellent, long protective sleeves, mosquito screens on windows and doors, and the cold, dry air of North American airconditioned houses are used to keep mosquitoes at bay. These objects recur throughout the New York Times coverage, suggesting that emotions and affective intensities arising around materiality structure Zika imaginaries.

Most importantly, materiality emerges as an affectively charged issue through its perceived ability to engender transgression of boundaries. A key site where this takes place is physical contacts between bodies. Social and cultural research on communicable diseases has shown that cultural and institutional concerns about outbreaks often center on the ways in which infected and not-yetinfected bodies come into close proximity or physical contact, leading to social or institutional sanctioning of specific modes of interaction and coexistence (e.g. Levina, 2015; Treichler, 1999; Wald, 2008). Although Zika is a vector-borne disease, there has emerged increasing evidence that the virus can also be contracted through bodily fluids - semen, blood, and possibly saliva and urine. This draws attention to the moments of bodily contact that pose a risk of transmission. In the New York Times articles, these moments emerge as affectively charged: Such moments may engender unforeseen personal and societal consequences, and thus they become sources of emotional investment and affective intensities. As in the case of HIV, sexual practices emerge as an object of particularly intense concern. Temporality intertwines with materiality here: Many of the New York Times articles imply that by controlling moments of material transgression we might be able to control the progression of the epidemic. The articles highlight several means of controlling such moments, including condoms, diagnostic tests, and even sexual abstinence, the full refusal to bring bodies into material contact perceived as risky. At the same time, this very need to control time - to control moments of material transgression and thus the progression of the epidemic - emerges itself as an affective force, as it shapes the social, material and emotional parameters of embodied experiences of intimacy and communality in Zika-affected areas.

Material boundaries become blurry also through the working of the entangled virus-mosquito entity. Apart from their shared invisibility discussed in the previous section, the virus and the mosquito appear as curiously inseparable also in how they are portrayed as unpredictable actors that 
transgress boundaries. The transgressions of the virus-mosquito entity are depicted through affectively charged, antagonistic language. The virus is described as 'stealthy' (Belluck, 2016d), 'vicious and unpredictable' and as engaging in a 'calamitous attack on the brains of babies' (Belluck, 2016b). Similarly, the Aedes aegypti mosquito is portrayed as 'a wily adversary' (Belluck, 2016e) with a 'taste for human blood' (Gillis, 2016), '[t] he most dangerous animal for humans by far' (Romero, 2016), and 'a real-life killer, one that claims more human lives each year than any other creature in the animal kingdom' (Santora, 2016a). In many of the texts, the same set of adjectives and nouns - dangerous, foe, enemy - are used to describe both the virus and the mosquito.

What makes the ontologically entangled mosquito-virus entity so affectively powerful is the way in which it is ascribed agency beyond human control. Again, this perceived agency centers on the dissolution of boundaries between organisms, embodied biological processes and geographical or social barriers. One of the earliest articles ponders 'how easily viruses are jumping from one part of the planet to another', forcing researchers to be 'alert' (Romero, 2015). Another article assigns the virus unpredicted agency by outlining the possibility that ' $[\mathrm{t}] \mathrm{he}$ virus has mutated and gotten worse' (Ramzy, 2016). The same applies to the mosquitoes as nonhuman agents: Humans appear as remarkably helpless as the mosquitoes 'stay one step ahead of the [insecticide] spray' (Belluck, 2016d). This portrayal of nonhuman agency mobilizes temporality, as if the virus and the mosquito were both able to manipulate time (the progression of the epidemic) while posing considerable obstacles to the forward-headed project of science. The virus and mosquito also emerge as controlling space: The virus is depicted as crossing geographical boundaries (e.g. Romero, 2015) and the mosquitoes 'know no boundaries' (Tavernise and McNeil, 2016). Here geographical boundaries converge with societal and bodily boundaries, with the result that boundarytransgressing powers of the virus and mosquitoes gain further symbolic weight and affective value. The perceived agency of the virus and the mosquito is strengthened by the evocation of invisibility. The tension between agency and invisibility emerges as a source of affect and emotions: The realization that something invisible can be agential renders nonhuman acts of boundarytransgression as objects of intense concern and anxiety. This invests the virus-mosquito entity with a heightened power to move emotions and the material realities of human life involving embodied illness, routes of transmission, sex and health care practices and the birth of children with microcephaly.

This affective power of nonhuman agency is particularly poignant in two news articles that discuss scientific studies of how the Zika virus affects nerve cells (Belluck, 2016a) and how it is able to cross the placenta and reach the fetus (Belluck, 2016c), published in May 2016 and July 2016 respectively. While both texts follow the conventions of science journalism by highlighting the exceptional cleverness of the design of the experiments and critical moments in the process of discovery, their general tone is gloomy rather than triumphant. This is because both studies reveal that the situation that triggered the study - Zika affecting the neurological development of the fetus - is considerably more grave than initially anticipated, and thus the studies reinforce rather than alleviate anxieties surrounding the epidemic. Both articles indicate that the earlier portrayal of the virus as sneaky does not fully capture the devastating changes that the virus can cause inside bodies. The virus emerges as a powerful and unpredictable actor, as it makes the infection materialize in cellular processes within human bodies, and ultimately in the material restructuring of the brains of babies - a frightening dissolution of material boundaries. The first of the articles depicts a series of in vitro experiments which show how the virus attacks different types of nerve cells. It shows that the virus turns some of these cells into 'factories' that produce more of the virus, thereby triggering a set of material processes with unknown future outcomes (Belluck, 2016a). The second article depicts two material routes through which the virus is able to evade the highly evolved placental 
defense mechanisms, which function to keep the fetus safe from external microbial threats. These processes suggest highly potent nonhuman agency, as when the virus 'attaches' to the 'helpful antibodies' that are allowed to cross the placenta to the fetus (Belluck, 2016c). This perceived nonhuman agency emerges as affectively charged through its ability to undo the boundaries between the interior and exterior of the uterus, and between familiar biological material and a foreign one.

In the two articles, the dissolution of material boundaries becomes entangled with temporality in a highly affective way: The moments when forward-oriented science makes visible these processes of nonhuman agency and materialization are horrible. They shake, they move, they unsettle ideas of what it means to be human in an age of emerging and re-emerging infectious diseases, to have no control over what is going on inside one's own body. These moments of discovery constitute foundational events that bring different temporalities - those of pregnancy, risky periods of contact, scientific progress and the progression of the epidemic - into collision, mobilizing and engendering a plethora of contradictory affective intensities and cultural emotions. At the same time, pregnancy in the time of Zika emerges as a phenomenon in which the past, present, and future fold into one another, as a past or present infection shapes potential futures. In this, it resembles what Mansfield (2017), working in the context of environmental epigenetics, calls 'the enduring present', the embeddedness of potential future outcomes in the present moment.

Finally, these accounts of the virus working inside pregnant bodies suggest that scientific attempts to visualize nonhuman agency and material processes might engender anxieties more than they alleviate them. It is also significant that the articles render the internal embodied materiality shaped by the virus as an ongoing process of materialization that pushes lives, bodies, and communities toward unforeseen futures. This processual nature posits embodied material processes in a productive tension with the multiple Zika temporalities discussed earlier in this article, since these temporalities contradict the temporal ambitions assigned to the material virus. At the same time, the ensuing temporal tensions produce ambivalence as to what we should feel and how we should react. Yet they engender a sense that, however we need to react, the moment is now, and that how we sense, feel, or react now may shape futures that emerge from the ongoing epidemic.

\section{Conclusion}

This article set out to develop methods of textual analysis for the study of the affective dynamics of technoscientific phenomena. My methodological exploration has been based on two premises: First, that understanding how affect and emotions organize multi-sited technoscientific phenomena requires analyzing textual material such as media texts, and second, that an analysis of such textual material needs to be able to capture not only representations of cultural emotions but also the ways in which texts are invested with affective intensities. While I draw on the analytical distinction between nondiscursive affect and culturally circulating emotions, I do not approach affect and emotions as ontologically separate entities, but view them instead as mutually entangled. I have sought to capture this entanglement by focusing on the affective dynamic that emerges at the intersection of discourse, narrative, and nondiscursive orientations. Such an understanding of affective dynamics brings together intensities, such as a sense of accelerating or halted movement, as well as cultural emotions, such as fears and hopes attached to particular material entities. Furthermore, the analysis has focused on tensions within the studied phenomenon, and thus on the complexity of affective intensities and emotional investments in technoscience. 
I have explored the affective dynamic of a specific technoscientific phenomenon, the Zika epidemic, by focusing on three affective concentrations: temporality, invisibility, and the dissolution of material boundaries. I have identified these affective concentrations through an analysis of repeated themes and ways of narrating and framing the epidemic in the New York Times. Yet these concentrations extend beyond phrases, vocabularies, and genre conventions; they also include the sense of emerging intensities that can move bodies, communities, and human destinies in often unpredicted ways. My reading of the New York Times coverage of the epidemic has shown, on the one hand, that each of these three affective formations is quite complex and contains contradictory elements, as when the different temporalities of the epidemic, science, and pregnancy emerge as entangled and yet repeatedly pulling in different directions. I have suggested that these underlying tensions and resonances are affectively potent, that is, they engender affective intensities and shape emotions. On the other hand, my analysis has demonstrated that these affective formations are mutually entangled. I have proposed that temporality, invisibility and dissolution of material boundaries intersect in ways that suggest, for example, that nonhuman entities (the Zika virus, the Aedes aegypti mosquito) may shape and control time; that the ways in which science makes visible embodied, material processes (such as the working of Zika inside the body) may produce unforeseen affective consequences; that the invisibility of an entity (such as the virus or the mosquito) does not make it appear as less materially threatening or powerful; and that despite the perceived future-orientation of science, science may not be in control of time or of material boundaries - and perhaps never was. These multivalent connections between the three affective concentrations operate as sources of affective intensification, reshaping emotional investments around the Zika epidemic.

The approach I propose in this article draws on the rich traditions of STS research that have explored emotional responses of patients, scientists and publics, as well as emotionally charged cultural representations of technoscience. At the same time, I have sought to connect the circulation of emotions at technoscientific sites to affective movements, tensions, and shifting intensities that underlie technoscientific phenomena. I have outlined an approach that enables interrogating the affective dynamics of technoscientific phenomena through textual material. As my analysis of the Zika epidemic shows, this approach involves identifying affective concentrations through recurring phrases, narrative elements, temporal arrangements, and underlying ambiguities. This provides then a basis for an analysis of internal tensions and resonances within those affective concentrations, as well as an examination of the connections - tensions, contradictions, resonances, parallelisms between the affective concentrations. I want to stress that this is by no means the only way that the underlying affective dynamics of technoscientific phenomena can be examined. The set of steps proposed here needs to be extended and elaborated to better capture the complexities of a range of technoscientific phenomena in many historical and geopolitical settings. This may take many paths, but it would likely involve combining textual analysis of affective dynamics with ethnographic research on embodied experiences. This expansion of focus could lead to the development of further analytical tools that can recognize formations of affective intensities and emotions across a range of phenomena - for example, connections between various epidemics, or between epidemics and clinical pharmaceutical trials.

My analysis of the New York Times coverage of the Zika epidemic provides an admittedly limited case study. It focuses on a single (albeit widely influential) news source located in a major metropolitan city in the global north. Despite its large international readership, the primary cultural framework of the New York Times is the United States. Although the articles were published in a number of sections within the paper, they nevertheless represent closely related genres of journalism. A larger selection of texts from different countries (including Brazil and Central American countries) and representing different genres (including popular culture, government 
documents, or focus-group interviews) would provide a more comprehensive ground for the theorization of the affective dynamics of technoscientific phenomena. Yet the very fact that the limited material used in this article was able to shed light on a considerable number of underlying complexities suggests that complex affective dynamics are not relevant only to large multi-sited, multi-genre sets of data. Affective dynamics are also crucial in the analysis of local textual sources. While it will be important to explore the affective dynamics of technoscientific phenomena through a diverse range of genres and sources, it is also important to recognize that a single source of data is structured by underlying affective dynamics. Finally, my case study shows that textual analysis does not need to be limited to representations or rhetoric of emotions. Textual analysis can be used to explore the ways in which affective intensities and cultural emotions co-structure technoscientific phenomena. Employed in this way, textual analysis is able to recognize some of the highly intricate ways in which science and technology affect our lives and communities.

\section{Notes}

1. See also, e.g. Koppman et al. (2015), Kowal (2013), Lorimer (2008), Pickersgill (2012) and Rees (2007).

2. See also, e.g. Danet and Medina-Doménech (2015), Haran and Kitzinger (2009), Höijer (2010), Horst (2005), Jensen (2008), Kimura (2017), Oikkonen (2015) and Väliverronen (2004).

3. E.g. Hong (2015), Kim (2009) and Sleenhoff et al. (2015).

4. E.g. Berlant (2011), Blackman (2012), Clough (2008), Hustak and Myers (2012), Massumi (2002), Myers (2015) and Protevi (2009).

\section{References}

Adams V, Murphy M, Clarke AE (2009) Anticipation: Technoscience, life, affect, temporality. Subjectivity 28(1): 246-265.

Ahmed S (2004) The Cultural Politics of Emotion. New York: Routledge.

Barad K (2007) Meeting the Universe Halfway: Quantum Physics and the Entanglement of Matter and Meaning. Durham, NC: Duke University Press.

Beer G (2000) Darwin's Plots: Evolutionary Narrative in Darwin, George Eliot and Nineteenthcentury Fiction. Cambridge: Cambridge University Press.

Belluck P (2016a) A race to unravel the secrets of the Zika virus. New York Times, 10 May: D1.

Belluck P (2016b) Brain scans of Brazilian babies show array of Zika effects. New York Times, 24 August: A1.

Belluck P (2016c) Confronting a lingering question about Zika: How it enters the womb. New York Times, 19 July: A9. 
Belluck P (2016d) Patch of Miami is ground zero for the Zika virus. New York Times, 9 August: A9.

Belluck P (2016e) Zika surge in Miami neighborhood prompts travel warning. New York Times, 2 August: A1.

Berlant L (2011) Cruel Optimism. Durham, NC: Duke University Press.

Blackman L (2012) Immaterial Bodies: Affect, Embodiment, Mediation. London: SAGE.

Clough PT (2008) The Affective turn: Political economy, biomedia and bodies. Theory, Culture \& Society 25(1): 1-22.

Cumming-Bruce N (2016) Zika vaccine still years away, W.H.O. says. New York Times, 9 March.

Danet A, Medina-Doménech RM (2015) A 'tale of two countries': Narratives of hearts, patients and doctors in the Spanish press. Public Understanding of Science 24(6): 641-657.

Dudo AD, Dahlstrom MF, Brossard D (2007) Reporting a potential pandemic: A risk-related assessment of avian influenza coverage in U.S. newspapers. Science Communication 28(4): 429454.

Evensen DT, Clarke CE (2012) Efficacy information in media coverage of infectious disease risks: An ill predicament? Science Communication 34(3): 392-418.

Franklin S (2007) Dolly Mixtures: The Remaking of Genealogy. Durham, NC: Duke University Press.

Garrett L (2016) Review: 'Zika' tracks the trajectory of an epidemic. New York Times, 29 July: C5.

Gillis J (2016) In Zika epidemic, a warning on climate change. New York Times, 21 February: A6.

Goodwin R, Haque S, Hassan SB, Dhanoa A (2011) Representations of swine flu: Perspectives from a Malaysian pig farm. Public Understanding of Science 20(4): 477-490.

Han S (2009) Seeing like a family: Fetal ultrasound images and imaginings of kin. In: Sasson VR, Law JM (eds) Imagining the Fetus: The Unborn in Myth, Religion, and Culture. Oxford: Oxford University Press, pp. 275-290.

Haran J, Kitzinger J (2009) Modest witnessing and managing the boundaries between science and the media: A case study of breakthrough and scandal. Public Understanding of Science 18(6): 634 652.

Hausman BL (2000) Do boys have to be boys? Gender, narrativity, and the John/Joan case. NWSA Journal 12(3): 114-138.

Hird M (2009) The Origins of Sociable Life: Evolution after Science Studies. Basingstoke: Palgrave Macmillan. 
Hirschfeld Davis J (2016) Zika fight requires more money, congress is told. New York Times, 12 April: A15.

Höijer B (2010) Emotional anchoring and objectification in the media reporting on climate change. Public Understanding of Science 19(6): 717-731.

Hong H (2015) Audience responses to television news coverage of medical advances: The mediating role of audience emotions and identification. Public Understanding of Science 24(6): $697-711$.

Horst M (2005) Cloning sensations: Mass mediated articulation of social responses to controversial biotechnology. Public Understanding of Science 14(2): 185-200.

Horst M (2007) Public expectations of gene therapy: Scientific futures and their performative effects on scientific citizenship. Science, Technology \& Human Values 32(2): 150-171.

Hotez PJ (2016) Zika is coming. New York Times, 9 April: A19.

Hustak C, Myers N (2012) Involuntary momentum: Affective ecologies and the sciences of plant/insect encounters. differences 23(3): 74-118.

Irni S (2016) Steroid provocations: On the materiality of politics in the history of sex hormones. Signs 41(3): 507-529.

Jacobs A (2016) Brazil pushes public to do its part in fighting Zika spread. New York Times, 15 February: A4.

Jensen E (2008) The Dao of human cloning: Utopian/dystopian hype in the British press and popular films. Public Understanding of Science 17(2): 123-143.

Joffe H (2011) Public apprehension of emerging infectious diseases: Are changes afoot? Public Understanding of Science 20(4): 446-460.

Joyce KA (2008) Magnetic Appeal: MRI and the Myth of Transparency. Ithaca, NY: Cornell University Press.

Kim J (2009) Public feeling for science: The Hwang affair and Hwang supporters. Public Understanding of Science 18(6): 670-686.

Kimura AH (2017) Fukushima ETHOS: Post-disaster risk communication, affect, and shifting risks. Science as Culture. Epub ahead of print 26 May. DOI: 10.1080/09505431.2017.1325458

Koppman S, Cain CL, Leahey E (2015) The joy of science: Disciplinary diversity in emotional accounts. Science, Technology \& Human Values 40(1): 30-70.

Kowal E (2013) Orphan DNA: Indigenous samples, ethical biovalue and postcolonial science. Social Studies of Science 43(4): 577-597.

Landecker H (2016) Antibiotic resistance and the biology of history. Body \& Society 22(4): 19-52. 
Levina M (2015) Pandemics and the Media. New York: Peter Lang.

Lorimer J (2008) Counting corncrakes: The affective science of the UK corncrake census. Social Studies of Science 38(3): 377-405.

McNeil DGJr (2016a) C.D.C. urges Zika testing for some who are pregnant. New York Times, 20 January: A3.

McNeil DGJr (2016b) Hawaii baby with brain damage is first U.S. case tied to Zika virus. New York Times, 17 January: A14.

McNeil DG, Saint Louis C (2016) Two studies strengthen links between the Zika virus and serious birth defects. New York Times, 5 March: A7.

McNeil M (2007) Feminist Cultural Studies of Science and Technology. New York: Routledge.

McNeil M, MacKenzie A, Tutton R (2017) Conceptualizing imaginaries of science, technology, and society In: Felt U, Fouché R, Miller CA, Smith-Doerr L (eds) The Handbook of Science and Technology Studies. Cambridge: MIT Press, pp. 435-464.

Macur J (2016) As Olympics near and Zika spreads, no talk of plan B. New York Times, 5 March: D1.

Mansfield B (2017) Folded futurity: Epigenetic plasticity, temporality, and new thresholds of fetal life. Science as Culture. Epub ahead of print 16 March. DOI: 10.1080/09505431.2017.1294575.

Masco J (2008) 'Survival is your business': Engineering ruins and affect in nuclear America. Cultural Anthropology 23(2): 361-398.

Massumi B (2002) Parables for the Virtual. Durham, NC: Duke University Press.

Mayor E, Eicher V, Bangerter A, Gilles I, Clémence A, Green EG (2013) Dynamic social representations of the $2009 \mathrm{H} 1 \mathrm{~N} 1$ pandemic: Shifting patterns of sense-making and blame. Public Understanding of Science 22(8): 1011-1024.

Meskus M (2015) Agential multiplicity in the assisted beginnings of life. European Journal of Women's Studies 22(1): 70-83.

Myers N (2015) Rendering Life Molecular: Models, Modelers, and Excitable Matter. Durham, NC: Duke University Press.

Nading AM (2014) Mosquito Trails: Ecology, Health, and the Politics of Entanglement. Oakland, CA: University of California Press.

New York Times (2016) Zika virus requires an urgent response. New York Times, 28 January: A28.

Oikkonen V (2013) Gender, Sexuality and Reproduction in Evolutionary Narratives. London: Routledge. 
Oikkonen V (2015) Mitochondrial Eve and the affective politics of human ancestry. Signs 40(3): $747-772$.

Osterholm MT (2016) How scared should you be about Zika? New York Times, 31 January: SR5.

Oudshoorn N (2015) Sustaining cyborgs: Sensing and tuning agencies of pacemakers and implantable cardioverter defibrillators. Social Studies of Science 45(1): 56-76.

Palmer J (2009) Seeing and knowing: Ultrasound images in the contemporary abortion debate. Feminist Theory 10(2): 173-189.

Parker JN, Hackett EJ (2012) Hot spots and hot moments in scientific collaborations and social movements. American Sociological Review 77(1): 21-44.

Pedwell C (2014) Affective Relations: The Transnational Politics of Empathy. Basingstoke: Palgrave Macmillan.

Pickersgill M (2012) The co-production of science, ethics, and emotion. Science, Technology \& Human Values 37(6): 579-603.

Prasad A (2005) Making images/making bodies: Visibilizing and disciplining through magnetic resonance imaging. Science, Technology \& Human Values 30(2): 291-316.

Protevi J (2009) Political Affect: Connecting the Social and the Somatic. Minneapolis, MN:

University of Minnesota Press.

Puig de la Bellacasa M (2015) Making time for soil: Technoscientific futurity and the pace of care. Social Studies of Science 45(5): 691-716.

Rabin RC (2016) In Florida, pregnant women cover up and stay inside amid Zika fears. New York Times, 20 August: A1.

Ramzy A (2016) Experts study Zika's path from first outbreak in Pacific. New York Times, 11 February: A12.

Rees A (2007) Reflections on the field: Primatology, popular science and the politics of personhood. Social Studies of Science 37(6): 881-907.

Roche JP, Muskavitch MAT (2003) Limited precision in print media communication of West Nile Virus risks. Science Communication 24(3): 353-365.

Romero S (2015) Alarm spreads in Brazil over a virus and a surge in malformed infants. New York Times, 31 December: A1.

Romero S (2016) Notes from the Zika beat: Heartbreak at the hospital. New York Times, 5 February.

Roof J (1996) Come as You Are: Sexuality and Narrative. New York: Columbia University Press.

Roof J (2007) The Poetics of DNA. Minneapolis, MN: University of Minnesota Press. 
Santora M (2016a) As experts confront the hazards of Zika, fear and uncertainty hover. New York Times, 2 July: A15.

Santora M (2016b) Twist in Zika outbreak: New York case shows women can spread it to men. New York Times, 16 July: A16.

Schell H (1997) Outburst! A chilling true story about emerging-virus narratives and pandemic social change. Configurations 5(1): 93-133.

Sleenhoff S, Cuppen E, Osseweijer P (2015) Unravelling emotional viewpoints on a bio-based economy using Q methodology. Public Understanding of Science 24(7): 858-877.

Stacey J (2010) The Cinematic Life of the Gene. Durham, NC: Duke University Press.

Tavernise S (2016a) Birth defects tied to Zika in Panama. New York Times, 23 March: A10.

Tavernise S (2016b) Prepare for 'guerrilla warfare' with Zika-carrying mosquitoes, experts warn. New York Times, 13 February: A1.

Tavernise S, McNeil DGJr (2016) Zika virus a global health emergency, W.H.O. says. New York Times, 2 February: A1.

Treichler PA (1999) How to Have Theory in an Epidemic: Cultural Chronicles of AIDS. Durham, NC: Duke University Press.

Turner SS (2007) Open-ended stories: Extinction narratives in genome time. Literature and Medicine 26(1): 55-82.

Väliverronen E (2004) Stories of the 'medicine cow': Representations of future promises in media discourse. Public Understanding of Science 13(4): 363-377.

Van Dijck J (1998) Imagenation: Popular Images of Genetics. Basingstoke: Macmillan.

Wald P (2008) Contagious: Cultures, Carriers, and the Outbreak Narrative. Durham, NC: Duke University Press.

Washer P (2010) Emerging Infectious Diseases and Society. Basingstoke: Palgrave Macmillan. 